\title{
Structural Analysis and Magnetic Properties of FeCo Alloys Obtained by Mechanical Alloying
}

\author{
F. Sánchez-De Jesús, ${ }^{1}$ A. M. Bolarín-Miró, ${ }^{1}$ C. A. Cortés Escobedo, ${ }^{2}$ \\ G. Torres-Villaseñor, ${ }^{3}$ and P. Vera-Serna ${ }^{4}$ \\ ${ }^{1}$ Área Académica de Ciencias de la Tierra y Materiales, UAEH, Carretera Pachuca-Tulancingo Km 4.5, 42184 Pachuca, HGO, Mexico \\ ${ }^{2}$ Centro de Investigación e Innovación Tecnológica del IPN, 02250 Ciudad de México, DF, Mexico \\ ${ }^{3}$ Departamento de Materiales Metálicos y Cerámicos, Instituto de Investigaciones en Materiales, \\ Universidad Nacional Autónoma de México, 04510 Ciudad de México, DF, Mexico \\ ${ }^{4}$ Laboratorio de Ingeniería Avanzada, Universidad Politécnica de Tecámac, 55740 Tecámac de Felipe Villanueva, MEX, Mexico
}

Correspondence should be addressed to A. M. Bolarín-Miró; anabolarin@msn.com

Received 8 March 2016; Revised 6 June 2016; Accepted 12 June 2016

Academic Editor: Gerhard Sauthoff

Copyright (C) 2016 F. Sánchez-De Jesús et al. This is an open access article distributed under the Creative Commons Attribution License, which permits unrestricted use, distribution, and reproduction in any medium, provided the original work is properly cited.

\begin{abstract}
A systematic study on the structural and magnetic properties of $\mathrm{Fe}_{100-x} \mathrm{Co}_{x}$ alloys $(10<x<90, \Delta x=10$ in wt. percent) obtained by mechanical alloying is presented. Elemental powders of $\mathrm{Fe}$ and Co mixed in an adequate weight ratio were milled at room temperature in a shaker mixer mill using vials and balls of hardened steel as milling media with a ball : powder weight ratio of $12: 1$. The mixtures were milled for $3 \mathrm{~h}$. The results show that, after milling, for almost all the composition (up to $x=60$ ), solid solutions based on bcc structures were obtained. For Co-rich alloys $(x \geq 70)$, different phases were found, revealing the formation of a metastable intermetallic phase (FeCo, wairauite) together with fcc-Co and hcp-Co phases. The specific saturation magnetization increases by increasing Co content, reaching a maximum value of $225 \mathrm{emu} / \mathrm{g}$ for hcp- $\mathrm{Fe}_{70} \mathrm{Co}_{30}$, and then it shows a diminution up to $154 \mathrm{emu} / \mathrm{g}$ for bcc- $\mathrm{Fe}_{30} \mathrm{Co}_{70}$. All studied alloys $\left(\mathrm{Fe}_{100-x} \mathrm{Co}_{x}\right)$ present low coercivity, in the range from 0 to $65 \mathrm{Oe}$, which is lower than reported. The coercivity increases with the increment in $\mathrm{Co}$, reaching a maximum of $64.1 \mathrm{Oe}$ for $\mathrm{Fe}_{40} \mathrm{Co}_{60}$. After that, the coercivity falls up to $24.5 \mathrm{Oe}$ for Co-rich alloys, which make them a very low coercive material.
\end{abstract}

\section{Introduction}

FeCo alloys are competitive candidates with other highly magnetic materials, because of their high specific saturation magnetization, low coercivity, high permeability, and high Curie temperature, properties which make them useful for applications at high temperature. The negative heat of mixing of Fe and $\mathrm{Co}\left(\Delta H_{\mathrm{FeCo}}=-1 \mathrm{~kJ} \mathrm{~mol}^{-1}\right)$ and the small mismatch between their atomic radii and electronegativity make the formation of FeCo alloys easy, interesting, and feasible $[1,2]$.

A great number of techniques have been used to synthesize the FeCo powders, like reduction reactions [3], plasmagas-condensation [4], wet chemical technique [5], and polyol [6]. Among the various synthesis methods, mechanical alloying (MA) is a method that creates a large number of crystal defects and stacking faults due to the severe plastic deformation that results from the high energy supplied to the system $[7,8]$. This enables structural changes such as allotropic transformations [9-11] which normally occur at high temperatures [12]. In addition, the magnetic properties of mechanically alloyed materials can be notably influenced by the MA process due to the stresses and defects that are generated during the milling process together with a consequent grain size reduction that results in enhanced magnetic behavior [13, 14].

Several studies have been published for the last years when $\mathrm{FeCo}$ alloys are synthesized by mechanical alloying. Moumeni et al. [15] and Akkouche et al. [16] reported that after $24 \mathrm{~h}$ of high-energy ball milling the formation of a Fe-bcc solid solution with $50 \%$ in wt. of Co was obtained. Laala-Bouali et al. [1] studied the relationship between the microstructure and the microhardness for the $\mathrm{Fe}_{70} \mathrm{Co}_{30}$ alloy 
(in wt.) obtained after $3 \mathrm{~h}$ of milling, finding interesting results about the formation of a Fe-bcc solid solution, while Bergheul et al. [17] focused their research on synthesis of $\mathrm{Fe}_{60} \mathrm{Co}_{40}$ alloy; they found that Fe-based alloys obtained by mechanosynthesis are promising materials for microwave absorbing devices.

Zeleńaková et al. [18] studied some compositions of the FeCo system; they synthesized nanocrystalline $\mathrm{Fe}_{100-x} \mathrm{Co}_{x}$ ( $x=40,50$, and 60 in $\%$ wt.) solid solutions by MA after $30 \mathrm{~h}$ of milling. The obtained alloys presented a disordered bcc$\mathrm{Fe}(\mathrm{Co})$ solid solution with coercivity showing an increment from 2450 to 4000 Oe for contents of 30 and $60 \%$ in wt. of Co, respectively. The specific saturation magnetization did not show a tendency with the content of Co, keeping its value between 225 and $203.5 \mathrm{emu} / \mathrm{g}$. Besides, Delshad Chermahini et al. [19] investigated the microstructure and magnetic properties of $\mathrm{Fe}_{100-x} \mathrm{Co}_{x}(x=10,45,50,77$, and 90) dedicated in the description of the mechanism of formation of the solid solution $\mathrm{Fe}_{100-x} \mathrm{Co}_{x}$ during the mechanical alloying process and the effect of the milling time in their structural and magnetic properties.

Due to the interesting effect of the mechanical alloying in their magnetic and mechanical properties, the interest in the FeCo alloy synthesized by this method has been increased during the last years, especially when this alloy is combined with other elements such as Mo [20, 21], V [22], Ni [23], Nb [24], and $\mathrm{Cr}$ [25] and even when these materials are used to obtain encapsulated carbon [26].

Even though there are a great number of interesting works in this subject, in all of them the milling times used to obtain the alloy are so high (higher than $20 \mathrm{~h}$ ) and there is not a complete study of the $\mathrm{Fe}_{100-x} \mathrm{Co}_{x}$ alloy in all the range of composition. Therefore, the aim of this work is to systematically study the magnetic properties of the $\mathrm{Fe}_{100-x} \mathrm{Co}_{x}$ alloy system with $10 \leq x \leq 90$ and $\Delta x=10$ synthesized by high-energy milling after a very short time (of $3 \mathrm{~h})$.

\section{Materials and Methods}

Elemental iron powder (Sigma-Aldrich, >99.9\%) with a mean particle size $\left(\mathrm{D}_{50}\right)$ of $2 \mu \mathrm{m}$ and cobalt powder (Sigma-Aldrich, $>99.9 \%$ ) with a mean particle size $\left(D_{50}\right)$ of $200 \mu \mathrm{m}$ were used as precursors. These differences in particle size were selected in order to promote homogeneous distribution of small particles of Co into Fe. The raw materials were mixed in the appropriate weight ratio to obtain $\mathrm{Fe}_{100-x} \mathrm{Co}_{x}$ alloys, where $x$ varies from 10 to 90 with $\Delta x=10$ in \% wt. A total amount of $5 \mathrm{~g}$ of the powder mixtures and 6 hardened steel balls with a diameter of $12.7 \mathrm{~mm}$ were loaded into a steel vial with $64.6 \mathrm{~cm}^{3}$ of volume and milled for $3 \mathrm{~h}$. According to previous results, a total solid solution is achieved after $3 \mathrm{~h}$ of milling [27]. This milling time is not sufficient to obtain only a solid solution without the presence of unmilled raw material (Fe and $\mathrm{Co}$ ). The mechanical alloying process was conducted at room temperature in an argon atmosphere using a SPEX $8000 \mathrm{D}$ shaker mill. The ball-to-powder weight ratio was $12: 1$. To prevent excessive overheating of the vials, all experiments were performed using cycles of 90 minutes of milling followed by 20 minutes of rest. The milled powders were analyzed by X-ray diffraction (XRD) for examining the phase transformations as a function of the alloy composition by a Siemens D5000 diffractometer. The diffraction parameters were collected with $2 \theta$ ranging from $40^{\circ}$ to $110^{\circ}$ with a step size of 0.02 and $\mathrm{Co}-\mathrm{K}_{\alpha}(\lambda=1.7889 \AA)$ radiation. Rietveld refinement was performed on the X-ray diffraction patterns using the program MAUD [28]. It was used to calculate the phase amount, cell parameters, and microstrain. This method takes into account all the information collected in a pattern, and it uses a least squares approach to refine a theoretical line until it matches the measured profile. The magnetic properties of the obtained materials, specific saturation magnetization $\left(M_{s}\right)$ and coercivity $\left(H_{c}\right)$, were measured using a MicroSense V7 vibrating sample magnetometer (VSM) with a maximum applied field of $18 \mathrm{kOe}$. Morphological characterization of the milled powders was performed using a JEOL JSM-6300 electron microscope operated at $15-30 \mathrm{kV}$.

\section{Results and Discussion}

3.1. Structural Analysis. Figures 1 and 2 show the XRD patterns of mixtures of elemental Fe and Co milled for $3 \mathrm{~h}$ to obtain $\mathrm{Fe}_{100-x} \mathrm{Co}_{x}$ with $x$ from 10 to $90: \Delta x=10(x$ as percentage in weight). In these figures, the XRD patterns corresponding to the mixture of the elemental powders, Fe and Co, without milling have been included. These patterns confirm the presence of three phases: bcc-Fe (COD 4113931, Im-3m bcc) and two allotropic structures of Co: Co- $\alpha$ (COD 9010968, Fm-3m) and Co- $\varepsilon$ (COD 9012950, P63/mmc) [29].

The XRD patterns shown in Figure 1 confirm the integration of $\mathrm{Co}$ atoms into the $\mathrm{Fe}-\mathrm{bcc}$ structure for compositions $\mathrm{Fe}_{100-x} \mathrm{Co}_{x}$ with $x$ from 10 to 40 , forming a complete bcc solid solution (Im-3m structure), since the Co-fcc and Cohcp reflection peaks, corresponding to the starting materials, have vanished, and only peaks corresponding to bcc-Fe are detected. As can be observed, when the cobalt level is increased, slight peak displacement is observed towards right, which is associated with a distortion of the crystal structure and variation in the cell parameter as a consequence of the plastic deformation in the early stage of milling. The Fe and Co radii are nearly similar. This distortion cannot be attributed to the incorporation of Co atoms into the Fe cell, due to the fact that $\mathrm{Co}$ and Fe radii are nearly similar (1.25 and $1.26 \AA$, resp.).

Different result was found for compositions with content in cobalt higher than $50 \%$ in wt., as can be observed in Figure 2, where different crystal structures were found for each composition. In addition, Rietveld refinement results are shown in Figure 2. It was observed that for $\mathrm{Fe}_{30} \mathrm{Co}_{70}$ a mixture of Fe-bcc/Im-3m and Co P63/mmc was formed, in good agreement with some authors [17, 18], while for a Co-rich alloy $\left(\mathrm{Fe}_{10} \mathrm{Co}_{90}\right)$ a mixture of phases was found: Fe-bcc/Im$3 m$, Fe P63/mmc, Co Fm-3m, and Fe P21 ma [3, 19]. Finally, for $\mathrm{Fe}_{20} \mathrm{Co}_{80}$ coexistence of two phases, one corresponding to $\mathrm{Fe}-\mathrm{bcc} / \mathrm{Im}$-3m (COD 9006597) and another metastable one, bcc-Co(Fe) (COD 9004228, Pm-3m), a cubic phase reported for the intermetallic FeCo, also called wairauite [30], was found. In this case, an exceptional experiment was carried 


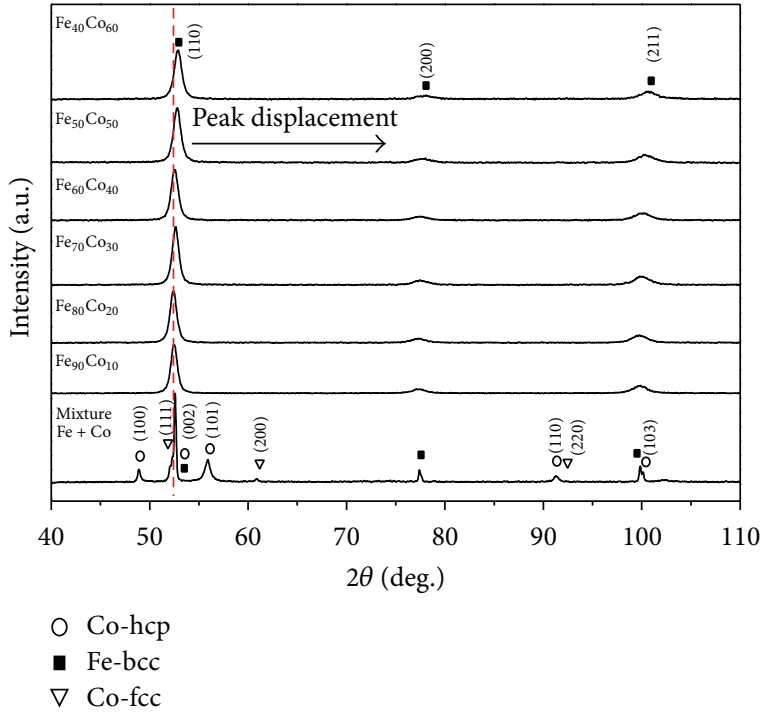

(a)

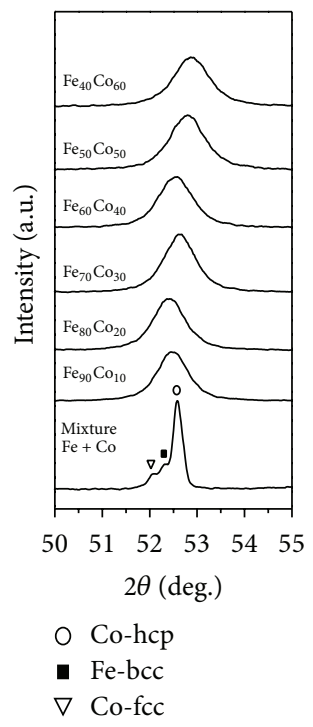

(b)

FIGURE 1: (a) XRD patterns of $\mathrm{Fe}_{100-x} \mathrm{Co}_{x}$ samples with $x$ from 10 to $60(\Delta x=10)$ milled for $3 \mathrm{~h}$. (b) Enlargement of the main peak.

on, increasing the milling time until $12 \mathrm{~h}$, confirming that, after this time, the two phases remain in the material (not shown in this paper). The formation of these metastable intermetallic phases is associated with synthesis method (mechanical alloying), which generates enough energy to produce unexpected and out of equilibria phases [13].

Broadening of reflection peaks for all the studied compositions can be observed in all the XRD patterns (Figures 1 and 2 ); it is related to the refinement of the microstructure and the increase in the lattice strain caused by the introduction of defects into the crystal structure during the mechanical alloying and also due to the formation of new solid solutions.

In order to quantify the obtained results by $\mathrm{X}$-ray diffraction, Rietveld refinement for all the composition was done using these patterns. Figure 3 presents a typical pattern of the results of the Rietveld refinement of mixtures of $\mathrm{Fe}$ and $\mathrm{Co}$ which were milled for $3 \mathrm{~h}$ in order to obtain $\mathrm{Fe}_{50} \mathrm{Co}_{50}$; this figure suggests high quality fit of the data with the refinement. This refinement was used to calculate the rms microstrain, cell parameter, and crystallite size of the obtained alloys. The obtained results of the refinement are shown in Table 1, which corroborate the formation of different solid solutions and give information about crystal parameters. As it is noticeable, Table 1 shows modifications in crystalline structure only in Co-rich compositions. For composition $\mathrm{Fe}_{100-x} \mathrm{Co}_{x}$ with $x$ down to 60, Fe-bcc solid solution is confirmed. For Co-rich alloys, an increment in the cell parameter is accompanied by the apparition of hexagonal and wairauite phases, which suggest that these transitional phases are intermediates for all the mixture of phases up to $\mathrm{Fe}_{10} \mathrm{Co}_{90}$ composition. These transitional phases provide high contributions to uncertainty; for this reason grain size and microstrain values calculated are not reliable because of the disorder generated.
From $\mathrm{Fe}_{90} \mathrm{Co}_{10}$ to $\mathrm{Fe}_{40} \mathrm{Co}_{60}$ a diminution in a cell parameter for bcc structure is observed, confirming the alloy formation, due to the incorporation of a smaller atom, such as substituting atoms of Co (metallic radii, $1.25 \AA$ ) for $\mathrm{Fe}$ (metallic radii, $1.26 \AA$ ) into the Fe-bcc (Pm-3m structure). This is produced by the severe plastic deformations together with an accumulation of large amount of structural defects during the milling process, modifying their final magnetic properties [15].

The crystallite size, shown in Table 1, depicts a large variation due to the formation of new phases and recrystallization of others. The formation of big crystallites shown in Table 1 is characteristic of the MA process when malleable powders are present because the materials are subjected to compressive forces between the grinding media causing the plastic deformation of particles and promoting the growing of the crystallite size [31], whereas the observed increment in crystallite size at the start of the compositional series, where iron is majority compound, is attributed to a major dislocation generation caused by severe plastic deformation and related to the formation of the $\mathrm{fcc}-\mathrm{Co}(\mathrm{Fe})$ solid solutions. As it was expected, the rms microstrain shows slight increment with the cobalt content, due to the incorporation of Co into the Fe-bcc and all the above mentioned defects. Meanwhile, Co-rich alloys show important increment in rms microstrain because of the disorder in their component phases.

3.2. Magnetic Characterization. Figure 4 shows the hysteresis $(M-H)$ curves for the $\mathrm{Fe}_{100-x} \mathrm{Co}_{x}$ alloys $(0 \leq x \leq 100)$. All the compositions show a similar magnetic behavior, low coercivity, and high specific saturation magnetization. Also, a significant increase in specific saturation magnetization is observed in between the compositions, with reference to pure Co, confirming a solid solution formation between pure elements 


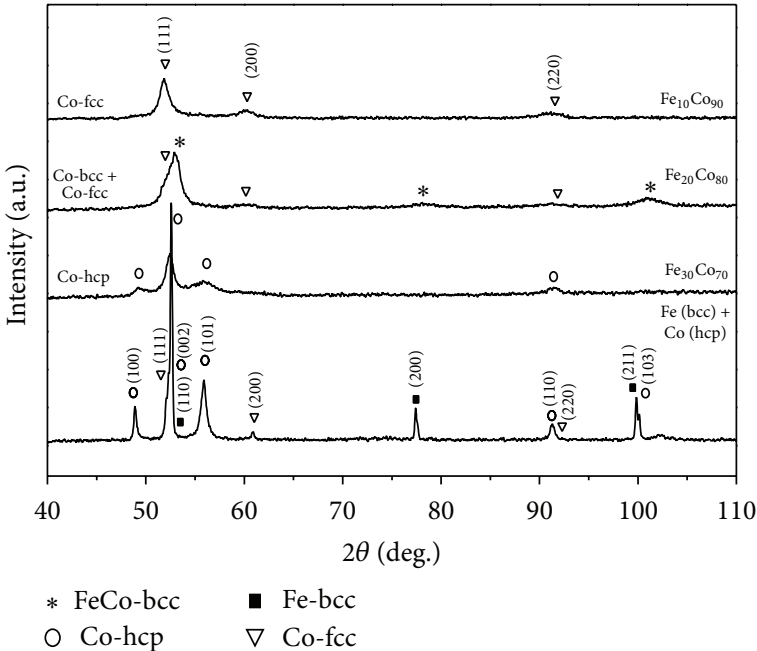

(a)
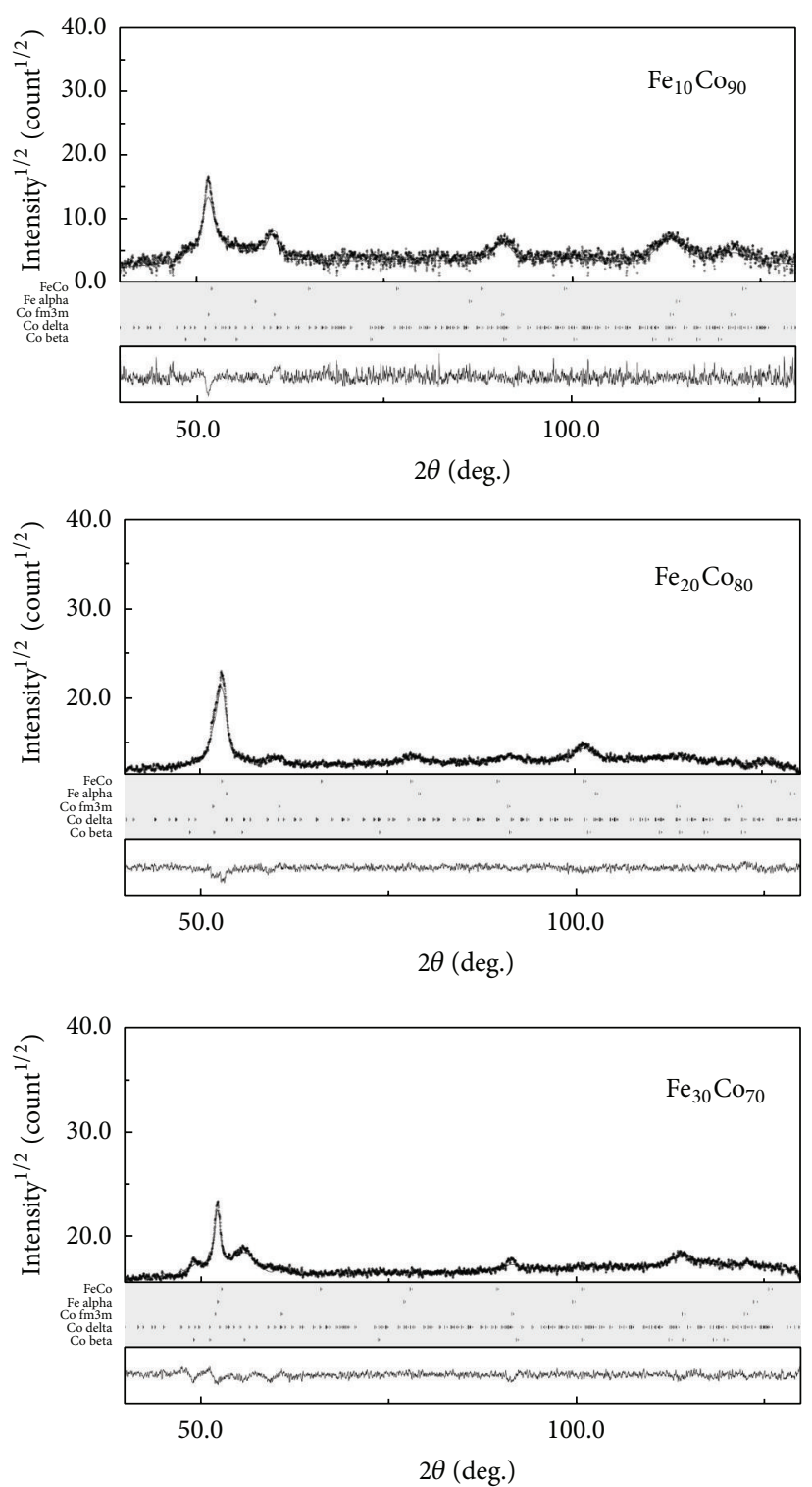

(b)

Figure 2: (a) XRD patterns of $\mathrm{Fe}_{100-x} \mathrm{Co}_{x}$ samples with $x$ from 70 to $90(\Delta x=10)$ milled for $3 \mathrm{~h}$. (b) Refined patterns.

( $\mathrm{Fe}$ and $\mathrm{Co}$ ) after the milling process. In order to analyze some of the most important magnetic properties of the milled powder, in Figures 5 and 6 , the magnetic parameters, specific saturation magnetization, $M_{S}$, and coercivity, $H_{c}$ (obtained from $M-H$ curves) versus the composition (content of Co, in wt.\%), are presented.

As it can be observed in Figure 5, $M_{S}$ increases as the cobalt content increases, up to $30 \%$ of cobalt, where the solution achieves a maximum value of $225 \mathrm{emu} / \mathrm{g}$, as is expected from Slater-Pauling curve, when the method of synthesis is under equilibrium conditions. Excluding the values of pure metals, the minimum value of $M_{s}$ was obtained for $\mathrm{Fe}_{30} \mathrm{Co}_{70}$ $(151.1 \mathrm{emu} / \mathrm{g})$, showing a value similar to the pure cobalt, about $150 \mathrm{emu} / \mathrm{g}$; it can be due to the stabilization of the hcp structure, as it was observed in the XRD patterns in Figure 2.

Unexpected values higher than $220 \mathrm{emu} / \mathrm{g}$ of specific saturation magnetization in $\mathrm{Fe}_{80} \mathrm{Co}_{20}, \mathrm{Fe}_{70} \mathrm{Co}_{30}$, and $\mathrm{Fe}_{60} \mathrm{Co}_{40}$ alloys were found; it may be due to the selfhood of the mechanical alloying process and the distortion produced during the process, changing the magnetic interactions. The specific saturation magnetization decreases drastically from $225 \mathrm{emu} / \mathrm{g}$ for $\mathrm{Fe}_{70} \mathrm{Co}_{30}$ to $151.1 \mathrm{emu} / \mathrm{g}$ for $\mathrm{Fe}_{30} \mathrm{Co}_{70}$. This noticeable decrease of $M_{S}$ can be attributed to the dilution effect of the magnetic moment of cobalt atoms promoted by the formation of the $\mathrm{Fe}(\mathrm{Co})$ and $\mathrm{Co}(\mathrm{Fe})$ solid solutions (structural change). 


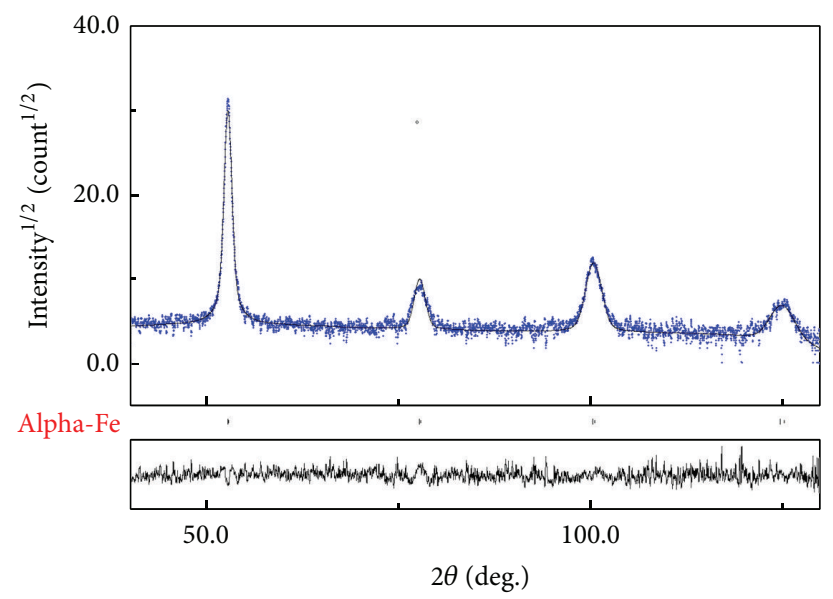

FIGURE 3: Rietveld refinement of X-ray powder diffraction pattern of a mixture of Fe and Co milled for $3 \mathrm{~h}$ in order to obtain $\mathrm{Fe}_{50} \mathrm{Co}_{50}$.

TABLE 1: Crystal structure, cell parameters, microstrain, and grain size from Rietveld refinement.

\begin{tabular}{|c|c|c|c|c|c|}
\hline Composition $\mathrm{Fe}_{100-x} \mathrm{Co}_{x}$ & Crystal structure/space group & $\%$ vol. & Cell parameter(s), $(a, b, c)(\AA)$ & rms, microstrain & Grain size $(\mathrm{nm})$ \\
\hline $\mathrm{Fe}_{90} \mathrm{Co}_{10}$ & $\mathrm{bcc} / \mathrm{Im}-3 \mathrm{~m}$ & 100 & 2.86 & 0.0035 & 294 \\
\hline $\mathrm{Fe}_{80} \mathrm{Co}_{20}$ & $\mathrm{bcc} / \mathrm{Im}-3 \mathrm{~m}$ & 100 & 2.87 & 0.0036 & 265 \\
\hline $\mathrm{Fe}_{70} \mathrm{Co}_{30}$ & $\mathrm{bcc} / \mathrm{Im}-3 \mathrm{~m}$ & 100 & 2.86 & 0.0039 & 286 \\
\hline $\mathrm{Fe}_{60} \mathrm{Co}_{40}$ & $\mathrm{bcc} / \mathrm{Im}-3 \mathrm{~m}$ & 100 & 2.87 & 0.0040 & 261 \\
\hline \multirow{2}{*}{$\mathrm{Fe}_{50} \mathrm{Co}_{50}$} & $\mathrm{bcc} / \mathrm{Im}-3 \mathrm{~m}$ & 50.3 & 2.85 & 0.0076 & 168 \\
\hline & $\mathrm{bcc} / \mathrm{Im}-3 \mathrm{~m}$ & 49.7 & 2.86 & 0.0052 & 2520 \\
\hline $\mathrm{Fe}_{40} \mathrm{Co}_{60}$ & $\mathrm{bcc} / \mathrm{Im}-3 \mathrm{~m}$ & 100 & 2.84 & 0.0041 & 234 \\
\hline \multirow{2}{*}{$\mathrm{Fe}_{30} \mathrm{Co}_{70}$} & Fe-bcc/Im-3m & 51.6 & 2.88 & 0.0001 & 165 \\
\hline & Co P63/mmc & 48.4 & $2.51,2.51,4.07$ & 0.0176 & 967 \\
\hline \multirow{2}{*}{$\mathrm{Fe}_{20} \mathrm{Co}_{80}$} & $\mathrm{Fe}-\mathrm{bcc} / \mathrm{Im}-3 \mathrm{~m}$ & 49.8 & 2.89 & 0.0062 & 103 \\
\hline & $\mathrm{FeCo}$ bcc/Pm-3m & 50.2 & 2.84 & 0.0029 & 96 \\
\hline \multirow{4}{*}{$\mathrm{Fe}_{10} \mathrm{Co}_{90}$} & Fe-bcc/Im-3m & 45.1 & 2.897 & 0.00005 & 102 \\
\hline & $\mathrm{Fe} \mathrm{P} 63 / \mathrm{mmc}$ & 46.1 & $2.35,2.35,3.81$ & 0.01767 & 892 \\
\hline & Co Fm-3m & 7.6 & 3.54 & 0.00482 & 977 \\
\hline & Co P21 ma & 1.2 & $7.94,7.9,15.3$ & 0.00029 & 1000 \\
\hline \multirow{4}{*}{$\mathrm{Co}, \mathrm{Fe}$} & Fe-bcc/Im-3m & 6.7 & 2.86 & 0.00063 & 2000 \\
\hline & Co P63/mmc & 43.3 & $2.51,2.51,4.07$ & 0.00012 & 240 \\
\hline & Fe Fm-3m & 7.2 & 3.54 & 0.00213 & 3209 \\
\hline & $\mathrm{Fe}-\mathrm{bcc} / \mathrm{Im}-3 \mathrm{~m}$ & 42.7 & 2.86 & 0.00086 & 3117 \\
\hline
\end{tabular}

For Co-rich alloys, the incorporation of Fe atoms into the fcc-Co and Co-hcp, together with the formation of transitional phase, bcc-Co, produces a remarkable increase in the specific saturation magnetization from 150 to $180 \mathrm{emu} / \mathrm{g}$ for 0 and $30 \%$ Fe in wt., respectively.

The coercivity behavior as a function of the cobalt content is shown in Figure 6. Alloys of $\mathrm{Fe}_{100-x} \mathrm{Co}_{x}$ present a similar behavior, high magnetization and low coercivity, in the range from 22 to $65 \mathrm{Oe}(0-4774 \mathrm{~A} / \mathrm{m})$ for all studied milled samples, which is lower than reported by other authors for the same compositions $[3,12,18,19]$, who found values of coercivity in the range of $25-100 \mathrm{Oe}(2-8 \mathrm{KA} / \mathrm{m})$ for nanocrystalline FeCo alloys obtained by different methods, including mechanical alloying.
In the studied milled mixtures, a tendency to increase from 22.4 to $64.1 \mathrm{Oe}$ for $\mathrm{Fe}_{90} \mathrm{Co}_{10}$ to $\mathrm{Fe}_{40} \mathrm{Co}_{60}$, respectively, is observed. In these compositions, a bcc- $\mathrm{Fe}(\mathrm{Co})$ alloy is completely formed and the incorporation of $\mathrm{Co}$-atoms into the bcc-Fe structure increases the residual stresses; therefore, $H_{c}$ increases, due to the coercivity being an extrinsic property of magnetic materials which strongly depends on the microstructure of the material including the effects of internal defects, residual stresses, grain sizes, and nonmagnetic inclusions [32]. After $60 \%$ of $\mathrm{Co}\left(\mathrm{Fe}_{40} \mathrm{Co}_{60}\right), H_{c}$ starts to fall up to 24.5 Oe for compositions upwards of $90 \%$ of cobalt. As is expected, the maximum value of coercivity $(205 \mathrm{Oe})$ is achieved by the material consisting of $100 \%$ Co, because it crystallizes in hexagonal crystal structure (hcp), which has 


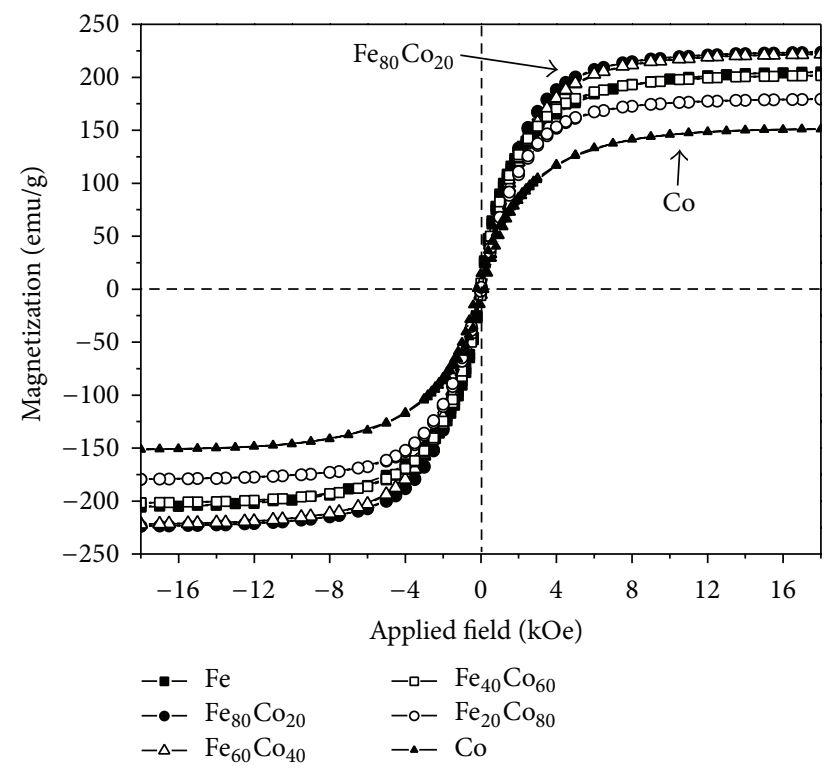

FIGURE 4: Hysteresis loops for $\mathrm{Fe}_{100-x} \mathrm{Co}_{x}$ alloys for different values of $x$.

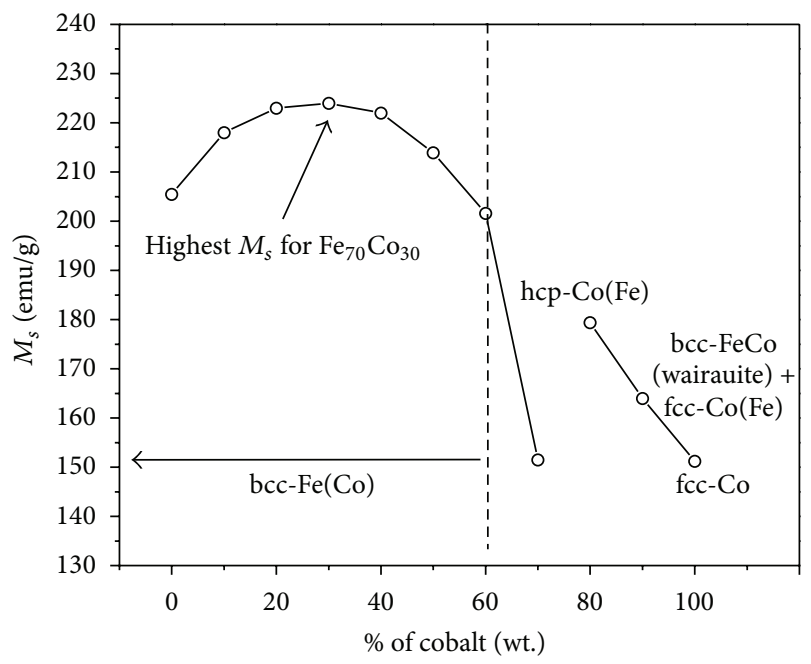

FIgURE 5: Specific saturation magnetization as function of Co content for $\mathrm{Fe}_{100-x} \mathrm{Co}_{x}$ alloys.

uniaxial crystalline anisotropy higher than that of the materials with cubic structure. The slight decreasing of $H_{c}$ observed for contents in cobalt higher than $60 \%$ may be explained as a consequence of the change of crystalline structure with respect to other compositions, that is, the obtaining of hexagonal hcp phase for $\mathrm{Fe}_{70} \mathrm{Co}_{30}$, cubic fcc phase for $\mathrm{Fe}_{10} \mathrm{Co}_{90}$, and cubic bcc phase for $\mathrm{Fe}_{20} \mathrm{Co}_{80}$. Also, a very interesting behavior is observed when $\mathrm{Fe}$ atoms are incorporated into the Co structure, promoting a decrease of $200 \%$ in its coercive field, as is noticeable in Figure 6. The coercivity is very much influenced by the residual stress, as well as the grain size, especially when mechanical alloying is used to obtain it.

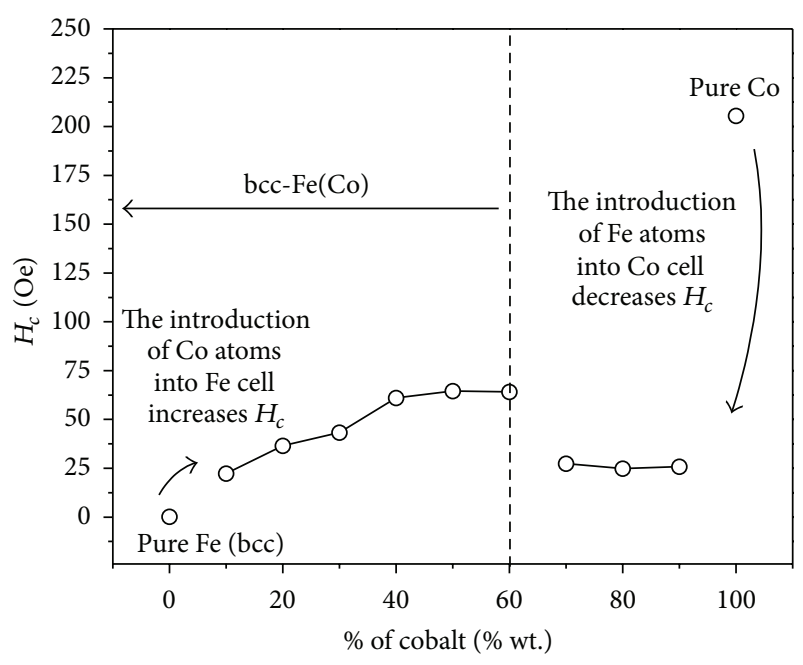

FIGURE 6: Coercivity field versus Co content for $\mathrm{Fe}_{100-x} \mathrm{Co}_{x}$ alloy.

3.3. Morphology. Figure 7 shows SEM micrographs that illustrate the morphology of the powder milled for the selected compositions. As can be observed, due to the repeated fracturing, cold welding, and agglomeration of the powders during the mechanical alloying, a noticeable change in the shape and size of the samples is obtained. The starting powders are so different in morphology and size; Co powder has a spherical-like morphology with few nanometers in size, while iron powder has irregular morphology with a particle size higher than 100 micrometers.

For all range of compositions, the milled powders show lamellar type morphology; flattened particles with irregular contours are observed, due to the plastic deformation induced during the milling process. It seems that particles of Fe are constantly fractured and joined into the lamellar particles; therefore, the increase of Fe content promotes a decrease in the particle size. On the other hand, the deformed particles of cobalt cover the iron particles, and it is for this reason that high cobalt contents promote the formation of large agglomerates.

\section{Conclusions}

Solid solutions of Co inserted into Fe-bcc structure were obtained by mechanical milling for $3 \mathrm{~h}$ in compositions $\mathrm{Fe}_{100-x} \mathrm{Co}_{x}$ with $x$ between 10 and $60(\Delta x=10)$ increasing its specific saturation magnetization with the increment in $x$ up to $225 \mathrm{emu} / \mathrm{g}$ for $x=30$. On the other hand, for $\mathrm{Fe}_{30} \mathrm{Co}_{70}$ a mixture of bcc and hcp phases was obtained. This composition results in the lowest specific saturation magnetization. Besides, for $\mathrm{Fe}_{20} \mathrm{Co}_{80}$, a mixture of wairauite intermetallic phase with fcc phase was found; this mixture of phases has lower value of coercivity than values reported previously. All the studied alloys $\left(\mathrm{Fe}_{100-x} \mathrm{Co}_{x}\right)$ present low coercivity, down to 65 Oe. For Co-rich alloys $(x>70)$, the coercivity falls up to $24.5 \mathrm{Oe}$. 

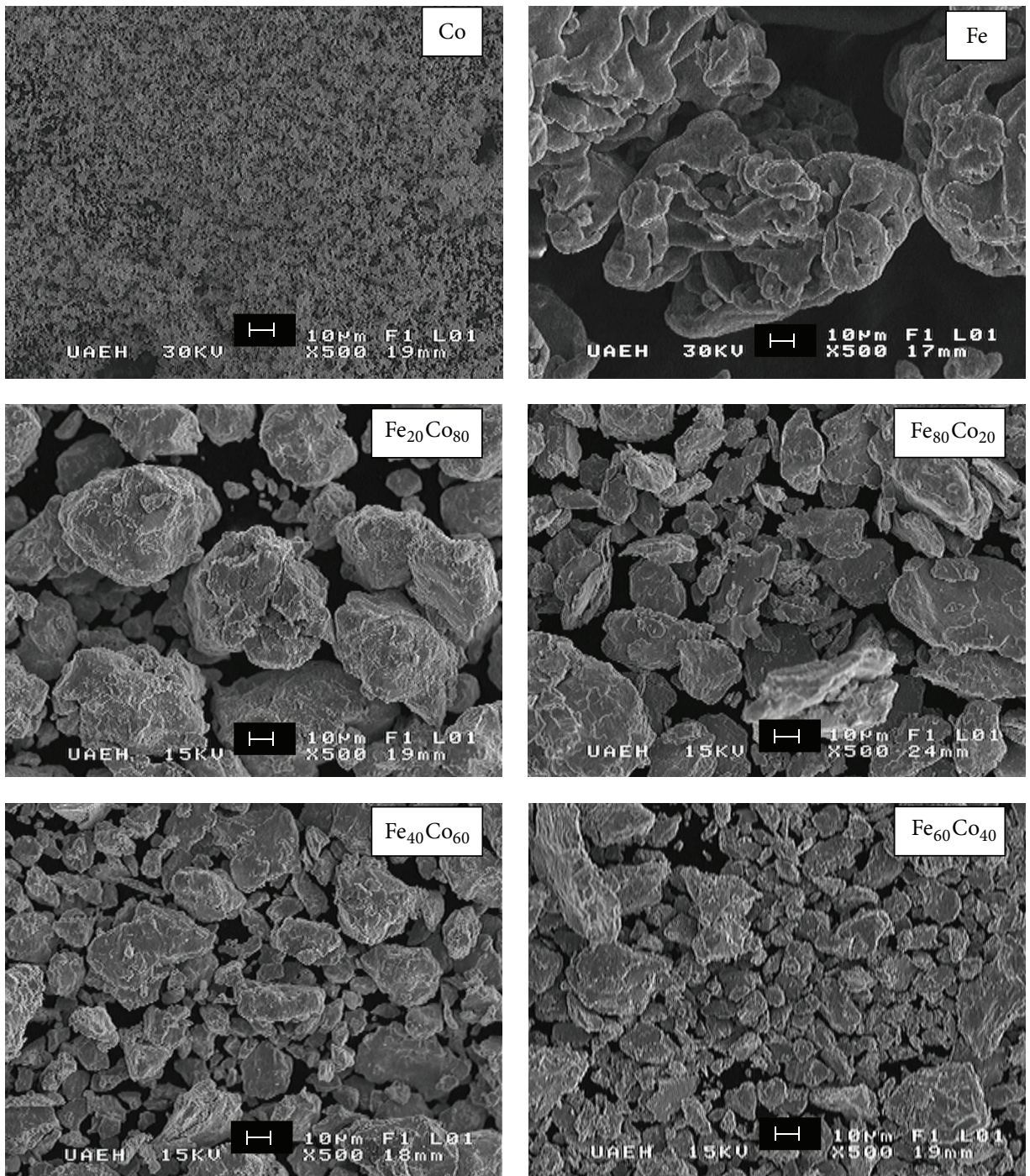

Figure 7: SEM micrographs of mixtures of Fe and Co milled for $3 \mathrm{~h}$ to obtain $\mathrm{Fe}_{100-x} \mathrm{Co}_{x}$.

\section{Competing Interests}

The authors declare that they have no competing interests.

\section{References}

[1] H. Laala-Bouali, F.-Z. Bentayeb, S. Louidi et al., "X-ray line profile analysis of the ball-milled Fe-30Co alloy," Advanced Powder Technology, vol. 24, no. 1, pp. 168-174, 2013.

[2] R. Satthawong, N. Koizumi, C. Song, and P. Prasassarakich, "Bimetallic Fe-Co catalysts for $\mathrm{CO}_{2}$ hydrogenation to higher hydrocarbons," Journal of $\mathrm{CO}_{2}$ Utilization, vol. 3-4, pp. 102-106, 2013.

[3] A. N. Popova, Y. A. Zaharov, and V. M. Pugachev, "Chemical synthesis, structure and magnetic properties of nanocrystalline Fe-Co alloys," Materials Letters, vol. 74, pp. 173-175, 2012.

[4] D. L. Peng, Y. Chen, H. She, R. Katoh, and K. Sumiyama, "Preparation and magnetic characteristics of size-monodispersed FeCo alloy cluster assemblies," Journal of Alloys and Compounds, vol. 469, no. 1-2, pp. 276-281, 2009.
[5] P.-S. Yuan, H.-Q. Wu, H.-Y. Xu, D.-M. Xu, Y.-J. Cao, and X.-W. Wei, "Synthesis, characterization and electrocatalytic properties of FeCo alloy nanoparticles supported on carbon nanotubes," Materials Chemistry and Physics, vol. 105, no. 2-3, pp. 391-394, 2007.

[6] M. Abbas, M. Nazrul Islam, B. Parvatheeswara Rao, T. Ogawa, M. Takahashi, and C. Kim, "One-pot synthesis of high magnetization air-stable FeCo nanoparticles by modified polyol method," Materials Letters, vol. 91, pp. 326-329, 2013.

[7] S. Alleg, F. Z. Bentayeb, R. Bensalem, C. Djebbari, L. Bessais, and J. M. Grenèche, "Effect of the milling conditions on the formation of nanostructured Fe-Co powders," Physica Status Solidi A, vol. 205, no. 7, pp. 1641-1646, 2008.

[8] S. Louidi, F. Z. Bentayeb, W. Tebib, J. J. Suñol, L. Escoda, and A. M. Mercier, "Formation study of nanostructured $\mathrm{Cr}_{100-x} \mathrm{Co}_{x}$ $(\mathrm{x}=10,90)$ alloys," Journal of Alloys and Compounds, vol. 536, no. 1, pp. S365-S369, 2012.

[9] M. D. Chermahini, S. Sharafi, H. Shokrollahi, and M. Zandrahimi, "Microstructural and magnetic properties of nanostructured $\mathrm{Fe}$ and $\mathrm{Fe}_{50} \mathrm{Co}_{50}$ powders prepared by mechanical 
alloying," Journal of Alloys and Compounds, vol. 474, no. 1-2, pp. 18-22, 2009.

[10] M. Delshad Chermahini, M. R. Rahimipour, and A. H. Pakseresht, "Microstructure and magnetic properties of nanostructured $\mathrm{Fe}-\mathrm{Co}$ powders prepared by series of milling and annealing treatments," Advanced Powder Technology, vol. 25, no. 1, pp. 462-466, 2014.

[11] J. A. Betancourt-Cantera, F. Sánchez-De Jesús, G. TorresVillaseñor, A. M. Bolarín-Miró, and C. A. Cortés-Escobedo, "Extended solid solubility of a Co-Cr system by mechanical alloying," Journal of Alloys and Compounds, vol. 529, pp. 58-62, 2012.

[12] J. Sort, J. Nogués, S. Suriñach, J. S. Muñoz, and M. D. Baró, "Correlation between stacking fault formation, allotropic phase transformations and magnetic properties of ball-milled cobalt," Materials Science and Engineering A, vol. 375-377, no. 1-2, pp. 869-873, 2004.

[13] A. M. Bolarín-Miró, F. S.-D. Jesús, G. Torres-Villaseñor, C. A. Cortés-Escobedo, J. A. Betancourt-Cantera, and J. I. BetancourtReyes, "Amorphization of Co-base alloy by mechanical alloying," Journal of Non-Crystalline Solids, vol. 357, no. 7, pp. 17051709, 2011.

[14] L. D’Onofrio, G. González, D. Oleszak, A. Sagarzazu, and R. Villalba, "Mössbauer study of Fe-Co alloys with Cr additions synthesized by mechanical alloying," Hyperfine Interactions, vol. 195, no. 1, pp. 167-171, 2009.

[15] H. Moumeni, S. Alleg, and J. M. Grenèche, "Structural properties of $\mathrm{Fe}_{50} \mathrm{Co}_{50}$ nanostructured powder prepared by mechanical alloying," Journal of Alloys and Compounds, vol. 386, no. 1-2, pp. 12-19, 2005.

[16] K. Akkouche, A. Guittoum, N. Boukherroub, and N. Souami, "Evolution of structure, microstructure and hyperfine properties of nanocrystalline $\mathrm{Fe}_{50} \mathrm{Co}_{50}$ powders prepared by mechanical alloying," Journal of Magnetism and Magnetic Materials, vol. 323, no. 21, pp. 2542-2548, 2011.

[17] S. Bergheul, F. Otmane, and M. Azzaz, "Structural and microwave absorption properties of nanostructured Fe-Co alloys," Advanced Powder Technology, vol. 23, no. 5, pp. 580-582, 2012.

[18] A. Zeleňáková, D. Olekšáková, J. Degmová et al., "Structural and magnetic properties of mechanically alloyed FeCo powders," Journal of Magnetism and Magnetic Materials, vol. 316, no. 2, pp. e519-e522, 2007.

[19] M. Delshad Chermahini, M. Zandrahimi, H. Shokrollahi, and S. Sharafi, "The effect of milling time and composition on microstructural and magnetic properties of nanostructured Fe-Co alloys," Journal of Alloys and Compounds, vol. 477, no. 1-2, pp. 45-50, 2009.

[20] H. Moumeni, A. Nemamcha, S. Alleg, and J. M. Grenèche, "Hyperfine interactions and structural features of $\mathrm{Fe}-44 \mathrm{Co}-$ $6 \mathrm{Mo}$ (wt.\%) nanostructured powders," Materials Chemistry and Physics, vol. 138, no. 1, pp. 209-214, 2013.

[21] M. Tavakoli, H. Shokrollahi, L. Karimi, and K. Janghorban, "Investigation of structural, microstructural and magnetic properties of mechanically alloyed nanostructured $\left(\mathrm{Fe}_{50} \mathrm{Co}_{50}\right)_{100-x} \mathrm{Mo}_{x}(\mathrm{x}=25,35)$ powders," Powder Technology, vol. 234, pp. 13-18, 2013.

[22] B. Chitsazan, H. Shokrollahi, A. Behvandi, and O. Mirzaee, "Characterization and magnetic coercivity of nanostructured $\left(\mathrm{Fe}_{50} \mathrm{Co}_{50}\right)_{100-X} \mathrm{~V}_{X}=0,2,4$ powders containing a small amount of $\mathrm{Co}_{3} \mathrm{~V}$ intermetallic obtained by mechanical alloying," Powder Technology, vol. 214, no. 1, pp. 105-110, 2011.
[23] H. Ahmadian Baghbaderani, S. Sharafi, and M. Delshad Chermahini, "Investigation of nanostructure formation mechanism and magnetic properties in $\mathrm{Fe}_{45} \mathrm{Co}_{45} \mathrm{Ni}_{10}$ system synthesized by mechanical alloying," Powder Technology, vol. 230, pp. 241-246, 2012.

[24] S. Nasibi, H. Shokrollahi, L. Karimi, and K. Janghorban, "Investigation of structural, microstructural and magnetic properties of mechanically alloyed amorphous/nanocrystalline $\mathrm{Fe}_{32.5} \mathrm{Co}_{32.5} \mathrm{Nb}_{35}$ powders," Powder Technology, vol. 228, pp. 404-409, 2012.

[25] F. Z. Bentayeb, S. Alleg, and J. M. Grenèche, "Structural and microstructural study of Fe-31Cr-12Co mixture prepared by ball milling," Journal of Alloys and Compounds, vol. 434-435, pp. 477-480, 2007.

[26] A. Wu, X. Yang, and H. Yang, "Magnetic properties of carbonencapsulated Fe-Co alloy nanoparticles," Dalton Transactions, vol. 42, no. 14, pp. 4978-4984, 2013.

[27] F. Sánchez-De Jesús, A. M. Bolarín-Miró, G. Torres-Villaseñor, C. A. Cortés-Escobedo, and J. A. Betancourt-Cantera, "Mechanical alloying of biocompatible $\mathrm{CoCr}_{28} \mathrm{Mo}_{6}$ alloy," Journal of Materials Science: Materials in Medicine, vol. 21, no. 7, pp. 20212026, 2010.

[28] L. Lutterotti, S. Matthies, and H. R. Wenk, "MAUD: a friendly Java program for material analysis using diffraction," $\mathrm{IUCr}$ Newsletter of the CPD, vol. 21, pp. 14-15, 1999.

[29] J. Y. Huang, Y. K. Wu, H. Q. Ye, and K. Lu, "Allotropic transformation of cobalt induced by ball milling," Nanostructured Materials, vol. 6, no. 5-8, pp. 723-726, 1995.

[30] P. Bayliss, "Revised unit cell dimensions, space group, and chemical formula of some metallic minerals," Canadian Mineralogyst, vol. 28, pp. 751-760, 1990.

[31] C. Suryanarayana, Mechanical Alloying and Milling, Marcel Dekker, New York, NY, USA, 2004.

[32] A. Behvandi, H. Shokrollahi, B. Chitsazan, and M. Ghaffari, "Magnetic and structural studies of mechanically alloyed nanostructured $\mathrm{Fe}_{49} \mathrm{Co}_{49} \mathrm{~V}_{2}$ powders," Journal of Magnetism and Magnetic Materials, vol. 322, no. 24, pp. 3932-3937, 2010. 

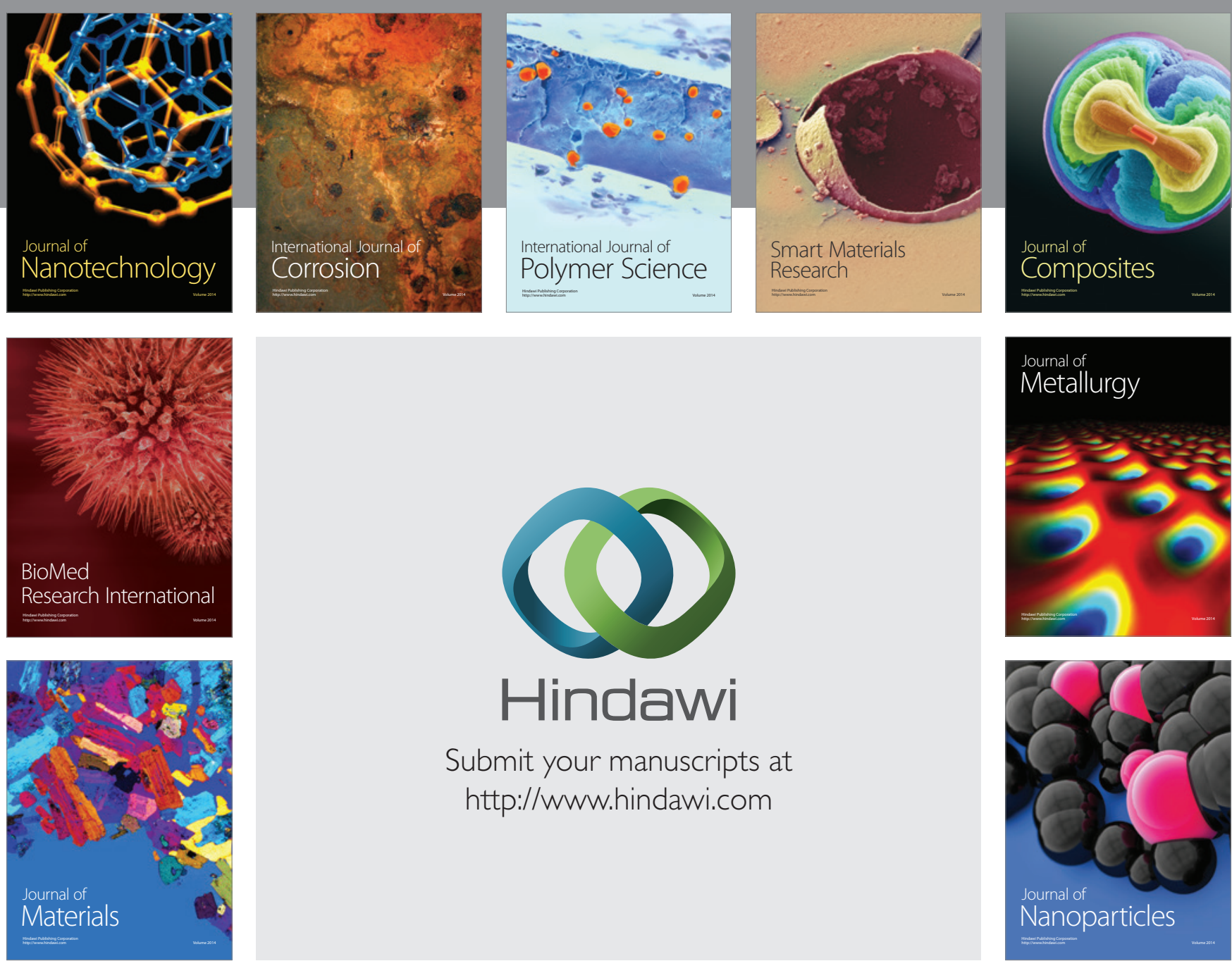

\section{Hindawi}

Submit your manuscripts at

http://www.hindawi.com

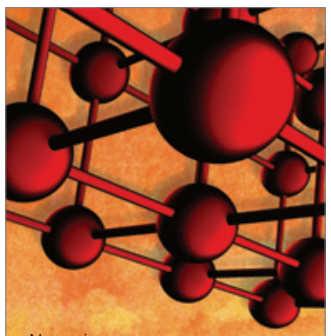

Materials Science and Engineering
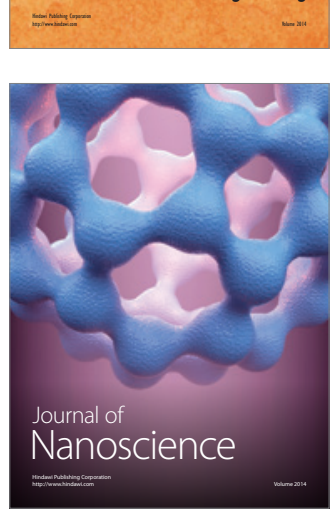
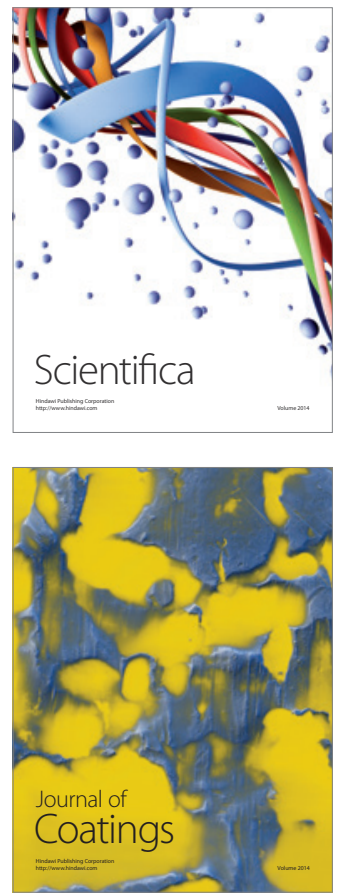
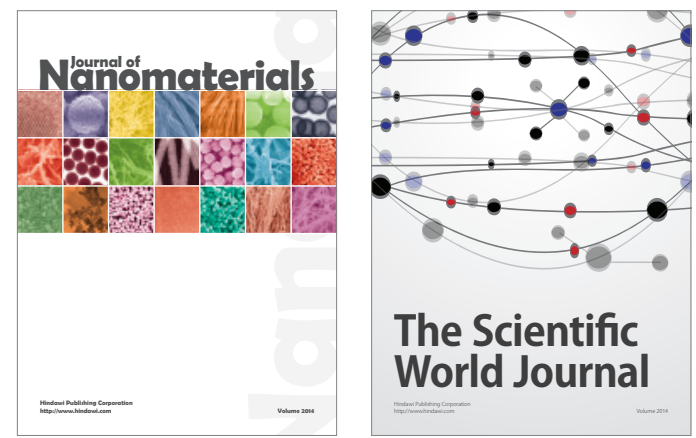

The Scientific World Journal
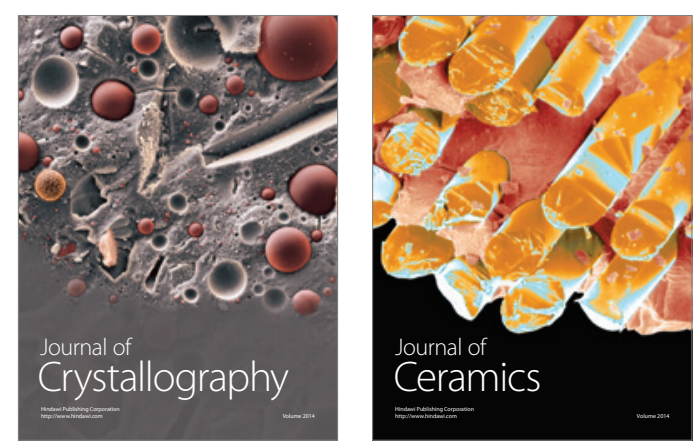
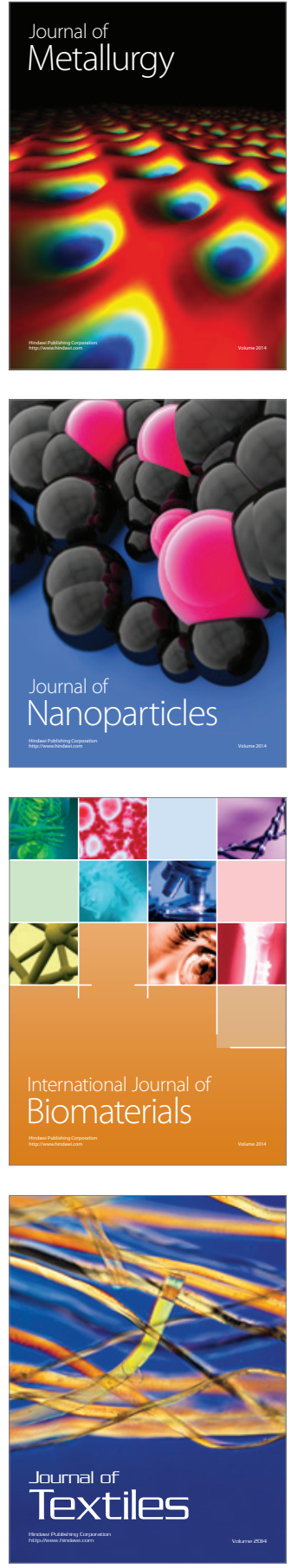